\title{
Military Social Work Thinking in South Africa
}

\section{Adrian D. van Breda}

\begin{abstract}
Military social workers in South Africa have developed distinctive ways of thinking about military social work. These developments have been influenced by various contextual factors, such as the transition of South Africa to a non-racial democracy in 1994 and the establishment of a military social work research capacity. These factors contributed to new ways of thinking, such as the recognition that military social work has a mandate to facilitate organizational change and the adoption of a resilience perspective. A central development in military social work thinking in South Africa was the formulation of a Military Social Work Practice Model, which is described and illustrated in some detail. This model emphasizes binocular vision (focusing on the interface between soldiers and the military organization) and four practice positions, derived from occupational social work theory. The author notes the importance of creating appropriate contexts that facilitate further developments in military social work theory.
\end{abstract}

Keywords: Military social work, ecosystems, person-in-environment, occupational social work, South Africa.

\section{INTRODUCTION}

The ten to fifteen years since 1994 have evidenced substantial growth in thinking about military social work (MilSW) in South Africa. South Africa's relative isolation from the rest of the world, due partly to our location on the southern tip of Africa and as a result of the sanctions during the dying years of Apartheid, resulted in the development of a rather distinctive approach to MilSW. This paper will show this distinctive approach and the kinds of factors that have influenced it.

This paper is focused primarily on how military social workers in South Africa think about MilSW practice, rather than in describing the history, structures and staffing of MilSW. It is the practice theories and approaches that are central to this paper. The paper will contend that MilSW thinking emerged in a particular context and evolved in ways that are distinct (though not entirely different) from militaries elsewhere in the world.

The paper opens with four contextual factors that I believe facilitated the evolvement of MilSW in South Africa. Particular attention is then given to a practice model of MilSW, which has been the guiding framework for all MilSW thinking and practice over the past 15 years, and brief practice examples illustrate how this thinking about MilSW guides the activities of social workers in South Africa. The paper concludes with some reflections on furthering the growth of MilSW thinking.

Prof. Adrian D. van Breda is an Associate Professor at the Department of Social Work at the University of Johannesburg, South Africa. Prof. van Breda was an active duty military social worker, in uniform, from 1991 to 2007, leaving the SANDF with the rank of Lieutenant Colonel.

Copyright (C) 2012 Advances in Social Work Vol. 13 No. 1 (Spring 2012), 17-33 


\section{THE SOUTH AFRICAN MILITARY SOCIAL WORK CONTEXT}

Military social work has formally existed in South Africa since 1968 (De Klerk, 1991). In the years leading up to 1994, seven separate military organizations were established in South Africa, including the South African Defence Force (SADF), the militaries of the four homeland states (the Transkei, Bophutatswana, Venda and Ciskei Defence Forces) and the armed wings of two liberation movements (Umkhonto we Sizwe (MK) and the Azanian People's Liberation Army (APLA)). Few social workers were employed by the homeland state militaries; most social workers were employed by the SADF, MK and APLA. It is of course true that during these years there was no partnering between social workers in the SADF and social workers in MK and APLA.

In 1994, with the collapse of Apartheid, these seven military organizations began a process of integration into the South African National Defence Force (SANDF). Currently, the SANDF employs approximately 130 social workers, most of whom are uniformed members and a handful are civilian employees. Ranks range from Lieutenant (the most junior rank for an entry-level military social worker) to Brigadier General (the Director Social Work).

The 10 or so years, starting from 1994, evidenced a rapid growth of thinking among military social workers. This is not to say there was no development before 1994 or in the past several years; rather, I have observed an intensification and flowering of new ideas during this ten-year period. One may go so far as to term this a 'golden era' in MilSW in South Africa. In this section I point to four major contextual factors that facilitated the growth and development of MilSW (Table 1).

Table 1. Developments in South African Military Social Work (MilSW)

\begin{tabular}{|l|l|}
\hline Contextual Factors & Development of MilSW \\
\hline Macro changes in South Africa in 1994 & Expanded insights into the role of MilSW \\
\hline Engagement with military families & New insights into deployment resilience \\
\hline $\begin{array}{l}\text { Establishment of a MilSW research } \\
\text { department }\end{array}$ & New MilSW social technologies \\
\hline Social work supervision course & A new model of MilSW practice \\
\hline
\end{tabular}

\section{Macro Changes in South Africa}

In 1994, the first democratic elections took place in South Africa, resulting in a handover of power from the National Party to the African National Congress. At the same time, and over the following years, the SADF was transformed into the SANDF, a composite of the seven former forces, welded into one new military force (Uys, 1997). Two key macro changes occurred that influenced MilSW thinking, through a change in the composition of MilSW personnel and shifts in the national welfare approach.

The integration of various forces and of various departments of social work introduced new thinking and insights about the nature and purpose of MilSW. SADF social workers had perhaps been conservative in the extent of change they felt free to 
facilitate, giving primary emphasis to micro-level change without challenging the status quo. By contrast, MK and APLA social workers had a much greater investment in social change, social justice and social action. These social workers grew up in the liberation movement and had embraced the liberation themes of transformation and revolution. Consequently, the understanding of the social work target system expanded from primarily individuals and families, to include the whole military system and even surrounding communities and society itself. A much more expansive sense developed of who social work served. Military social workers also appropriated a mandate for organizational change, ensuring that the social environment of soldiers (which is used as a collective noun in this paper, including all military employees and their families) was conducive to well-being. A somewhat more radical approach to social work thus evolved after 1994.

Post-1994 social workers got involved in the ANC government's Reconstruction and Development Programme (RDP), which called for a much more holistic engagement with the needs of all peoples and for work at a structural and institutional level, not just at the level of individuals and communities (ANC, 1994). The RDP led, a few years later, to the White Paper for Social Welfare (RSA, 1997), in which South Africa adopted a developmental approach to social welfare (Midgley, 2001). Much effort was invested in coming to terms with what this approach meant for MilSW. Developmental welfare calls for a bridging of the micro-macro divide (Patel, 2005), which had been characteristic of pre-1994 MilSW in the SADF. Furthermore, it advances a rights-based approach and an increase in democracy and people's participation in their own welfare (Patel, 2005), supported by the Bill of Rights and the South African Constitution (RSA, 1996). This further facilitated a shift from paternalistic social work towards a more radical approach to social work.

As a result of these macro changes, MilSW thinking became more radical, more willing to challenge the status quo, more willing to engage in macro change processes and more committed to listening to and being guided by the needs and rights of the military workforce.

\section{Engagement with Military Families}

A second paradigm shift emerged in response to the engagement of military social workers at the Institute for Maritime Medicine with military families in the mid-1990s. Naval wives had established a support network to help them deal with the absence of their husbands (at that time only men could serve on naval vessels). Navy social workers were invited to partner with this network and together evolved a comprehensive system of support to Naval families. This engagement with a group of women who had taken the initiative and in which social workers were 'tagging along' facilitated a new recognition of the coping resources of military families. An article by Logan (1987) was particularly influential in prompting the study of resilience literature (McCubbin's work was particularly influential, e.g. McCubbin \& Lavee, 1986).

MilSW's engagement with resilient families and encounter with literature on family resilience led to the coining of the term 'deployment resilience'. Previously, social workers were interested primarily in the ways in which deployments stress families and contribute to their breakdown (Van Breda, 1997b) - what Antonovsky (1988) calls a pathogenic perspective. However, from the mid-1990s emphasis shifted 
to uncovering and then developing mechanisms that families had evolved to cope with deployments (Van Breda, 1998; 1999).

Resilience theory (Van Breda, 2001) sparked a new way of thinking about military families. They were not passive victims of the military system. Nor were they inevitably dysfunctional and damaged. Rather, families were recognized as having inherent skills, abilities and talents, which helped them thrive in the face of the challenges of living in a military environment. This new way of thinking about military families, and about the military itself, emerged at around the same time as Saleebey's book on the 'strengths perspective' in social work (Saleebey, 2008).

The practice implications of a resilience approach to social work practice became rapidly evident and have continued to impact on MilSW in the SANDF. The first was the design of a Deployment Resilience Seminar (Van Breda, 1999), a one-day program aimed at teaching all military families the coping skills and patterns that resilient families had discovered for themselves. Several other resilience programs were developed thereafter, for example, focusing on single soldiers or soldiers whose families lived far away from the military base, often in rural areas.

Some years later, military social workers developed an assessment model and scale for screening soldiers prior to deployments, as part of the military's concurrent health assessments (Van Breda, 2002b). This process, which included a conceptual model for assessment, a standardized rating scale and a standardized clinical interview schedule, was similarly grounded in resilience theory (Van Breda, 2008; 2011).

Through their close engagement with military families, MilSW began to incorporate an appreciation for the strengths and coping resources of military families. This was enriched through intensive reading on resilience, and particularly international literature on the resilience of military families. MilSW thinking became more strengths-oriented and this has influenced virtually all subsequent developments in MilSW in South Africa.

\section{Social Work Research Department}

A third key factor that facilitated the development of MilSW thinking was the establishment of the first social work research department in the SANDF in 1997 (Van Breda, 2002a). Initially staffed with just one social worker, and located in the Military Psychological Institute, the department grew over the subsequent four years to five posts. This initiative was vital to the growth of MilSW, in setting aside a team of social workers, each with several years of MilSW practice experience, to give dedicated attention to thinking about MilSW and to develop new knowledge and interventions for the organization. Social work practitioners are preoccupied with practice in their own sphere of responsibility; social work managers are preoccupied with performance management and the budget; social work researchers have the space to think and innovate.

This department, during its first several years of existence, developed the concurrent health assessment model and tools mentioned previously, a new management information system based on a model of MilSW practice, a range of new courses and interventions (such as a program for soldiers with financial challenges), research on family violence, HIV KAP studies, and a massive HIV peer-training 
program. In recent years, much effort has been invested in monitoring and evaluating PEPFAR-funded HIV programs in the SANDF.

The provision of a dedicated research capacity within social work opened up space for intensified thinking about MilSW and the translation of these ideas into models and tools for social work practice and management.

\section{Social Work Supervision Course}

The fourth contextual factor that facilitated growth was the implementation of a series of social work supervision courses, headed by Arista Bouwer, a military social worker with a wide vision for social work. The courses were run to develop a cadre of senior social workers who could supervise younger social workers and contribute to the development of the quality of social work services in the SANDF. In the 1990s, this course incorporated the requirement to develop new social technologies for the social work department, thus serving to stimulate new thinking about and the evolvement of MilSW.

In 1997, Alida Kruger and I (who were students on this course) were tasked to develop a model of MilSW practice. This model was widely reviewed by social workers throughout the SANDF and underwent a number of revisions. It has become the foundation of MilSW thinking and practice in the SANDF, guiding practice and shaping reporting requirements (Kruger \& Van Breda, 2001). For example, the model is a key element of the induction training provided to all new social workers. In addition, a management information system was developed that required practitioners to report on their professional activities according to the four practice positions of the model.

Part of what was distinctive about this model was that it was grounded in occupational social work theory. Occupational social work was burgeoning in South Africa at the time, particularly in the mining industry, thanks in particular to Angela du Plessis, who ran a masters program in industrial social work at the University of the Witwatersrand (Du Plessis, 2001). Several SANDF social workers did this course and brought this theory into MilSW thinking.

This marrying of military and occupational social work lent a distinctive flavor to how social workers in the South African military think about their practice. Some military social workers in the USA, for example, have shaped their understanding of MilSW on clinical social work (e.g. Applewhite, Hamlin, BrintzenhofeSzoc, \& Timberlake, 1995) or employee assistance programs (e.g. Ortiz \& Bassoff, 1987). Both of these forms of social work tend towards a micro and therapeutic approach to social work practice. By contrast, occupational social work endeavors to work not only with employees, but also with the organization as client, promoting a more integrated and holistic approach to social work practice.

The provision of intensive training opportunities that incorporated an expectation of innovation in MilSW facilitated the development of new technologies for MilSW practice. The incorporation of occupational social work theory lent MilSW thinking a distinctive flavor, through its interest in facilitating organizational change. 


\section{THE MILITARY SOCIAL WORK PRACTICE MODEL}

In the preceding section I proposed four key contextual factors that occurred in South Africa in the years following 1994 and the ways in which these factors contributed to the evolvement of MilSW thinking in the SANDF. In this section I aim to give particular emphasis to one of those developments, namely the Military Social Work Practice Model (MilSWPM).

\section{Occupational Social Work}

As previously mentioned, MilSW in the SANDF has been influenced by occupational social work literature, though not uncritically. MilSW's initial thoughts about occupational social work were influenced primarily by the theoretical models developed by Googins and Godfrey (1987) and Ozawa (1980). Both models describe the development or "evolvement" of occupational social work practice "along the continuum from micro to macro" (Du Plessis, 1994, p. 91). These models were valuable in shaping the evolvement of MilSW in South Africa, and especially in challenging social workers towards more organizationally-based, macro activities. Nevertheless, they were found to be insufficient to guide military social work practice.

The key concern was with the notions of 'phases' or 'stages' (Googins \& Godfrey, 1987; Ozawa, 1980). Military social workers in the SANDF tended to understand these terms to mean that in order to progress towards the higher and more sophisticated levels of practice they must abandon the individual as client in favor of the organization as client. These terms suggest that when one moves on to a next phase, the previous phase becomes of lesser importance or even irrelevant. Stage models of occupational social work are flawed because they are progressive, not additive - that is, they involve leaving one stage to progress to the next, rather than adding the stages together.

This tendency is mirrored in the use of the expression 'micro-macro continuum' (Du Plessis, 1994; Googins, 1987; Googins \& Davidson, 1993). Du Plessis (1994, p. 169) locates occupational social workers along this continuum based on their emphasis on micro versus macro practice. A continuum, however, is a linear, twodimensional construct that does not correlate with our organic and multifaceted reality. Postmodernist and systems theories reject linear models for this reason. When one places micro interventions at one end of a line and macro interventions at the other, micro and macro become polarized and thus mutually exclusive. Writers who use the micro-macro metaphor are forced, by the essential limitation of the metaphor, to repeatedly stress that macro interventions should be added to, rather than replace, micro interventions (e.g. Du Plessis, 1994, p. 169; Googins, 1987, p. 49).

These metaphors of 'stage' and 'micro-macro continuum' inadequately reflect the reality of social work practice, consequently confusing the developmental aspirations of social workers. In essence, they do not allow for the integration of different forms of intervention. This is reflected in the on-going debate in the literature regarding "Who is my client?" The answer has centered on the micro-macro distinction between the 'employee-as-person' and the 'person-as-employee' (Spiegel, in Du Plessis, 1994). This has been augmented by the notion of the 'organization as client' (Googins \& Davidson, 1993). While these three conceptions of the occupational 
social worker's clients are helpful, they are not integrated, and thus inadequately guide MilSW practice.

In response to these limitations, the SANDF developed a new MilSWPM in 1997. The MilSWPM aimed to integrate the various 'stages' of occupational social work, in line with developmental social welfare's call to bridge the micro-macro divide, to transform the micro-macro continuum from a line to a circle, and to address all potential client systems. It was hoped that the model would shape an understanding that MilSW development is not through a series of stages along a continuum, but rather, that development involves an expanding role, in which one gradually grows into a more comprehensive practitioner.

\section{Binocular Vision}

Social work is guided by various theories, most central of which is, arguably, ecosystems theory (Gitterman \& Germain, 2008). Central to ecosystems is the notion of what Gordon Hamilton termed 'the-person-in-situation' which highlights the "threefold configuration consisting of the person, the situation, and the interaction between them" (Hollis \& Woods, 1981, p. 27, emphasis added). However, social workers frequently struggle to think ecosystemically, and have a tendency to focus on either the person or the environment (i.e. the soldier or the military system), rather than on the integrated person-in-environment. Consequently, the MilSWPM proposes a new metaphor to facilitate the grasp of the notion of person-in-environment, viz. 'binocular vision'.

Wilfred Bion, the British psychoanalyst, proposed the term 'binocular vision' to describe a way of simultaneously seeing one thing with one eye and another thing with the other eye (in Casement, 1985, p. 4). This metaphor is adapted to suggest that the one lens is microscopic (looking at the individual and family), while the other is telescopic or 'macroscopic' (looking at the military organization). Binocular vision occurs when we simultaneously look through the microscopic and telescopic lenses. To close one or other eye is to lose one's depth perception, to lose half one's vision, which is to become handicapped in one's work.

Bateson used the metaphor of binocular vision in a similar way. He says (in Keeney, 1983, p. 37), "It is correct (and a great improvement) to begin to think of the two parties in an interaction [e.g. the soldier and the military] as two eyes, each giving a monocular view of what goes on and, together, giving a binocular view in depth. The double view is the relationship.”

Binocular vision thus enables one to see a whole situation in greater depth, enhancing the quality and scope of assessment and intervention. It also shifts the focus off the two separate client systems and onto the relationship or interface between them. This relationship then becomes the client, much as in marital counseling the relationship is often defined as the client. Inherent in binocularity is social work's commitment to promoting the fit between people and their situations or environments.

The utility of binocularity for the military social worker is to provide a metaphor that will assist in making sense of the tension between commitment to the soldiers' interests and commitment to the military's interests. The MilSWPM contends that there ought to be tension in this area of MilSW, since it is only in the presence of 
tension that true binocularity is achieved (Googins, 1987). At the fulcrum of soldierand-military lies the immense creative potential of MilSW. The metaphor of binocular vision assists military social workers in South Africa to remain at this fulcrum.

Binocular vision's creative potential can be realized by seeking out the most problematic point of interface between soldiers and the military. The cutting edge of MilSW can be located at this point. The following four questions can assist in identifying this point:
* What are the unique demands the military places on its members?
* What are the unique demands soldiers place on the military?
* What human skills are required by members to be effective in their work?
* What organizational systems/structures are essential to ensure military readiness?

By addressing themselves to the point at which the military and soldier fit least well, military social workers are able to ensure that they play a pivotal role in the achievement of the military's mission and in the well-being of soldiers and their families. In business terminology, the social worker's ability to facilitate these problematic points of interface is one of the organization's critical success factors.

\section{The Military Social Work Practice Model}

The MilSWPM endeavors to move away from the language of 'stages' that was found to be a limitation of much occupational social work literature. Instead, the model uses the term 'position', which was coined by Melanie Klein (the postFreudian child analyst). Klein (in Hinshelwood, 1991, p. 393) used the term to avoid the sense of prescriptive progression through Freud's psychosexual stages of development, as well as to describe the positions from which a human child or adult may view the external world and experience the internal world.

The MilSWPM's preference for the concept 'position' is not mere semantics. It allows for a greater fluidity of movement between positions. Positions are less value laden, so that one position is not necessarily better or more important than another position, merely more appropriate. A practice model comprising positions is more organic and holistic than one comprising stages/phases. It avoids the pitfalls of linear thinking by ensuring circularity.

The MilSWPM, therefore, comprises four practice positions from which a military social worker may intervene (Figure 1). Each position describes a different way of perceiving a problem, a client, an intervention or one's own role. The four positions, which will be described below in some detail, are:

\begin{tabular}{|l|l|}
\hline Position One: & Restorative Interventions \\
\hline Position Two: & Promotive Interventions \\
\hline Position Three: & Work-person Interventions \\
\hline Position Four: & Workplace Interventions \\
\hline
\end{tabular}


Figure 1. Military Social Work Practice Model

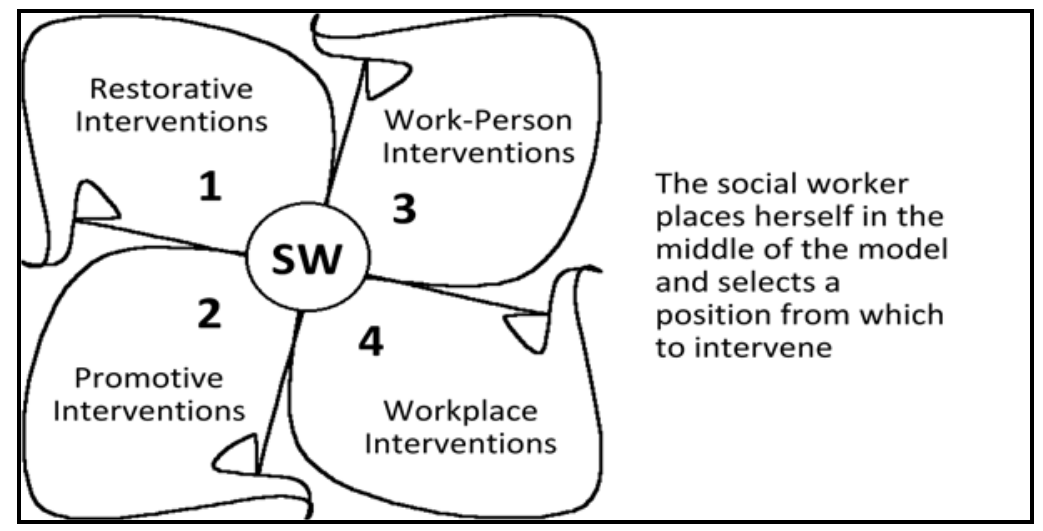

\section{Position One: Restorative Interventions}

In this position the military social worker renders a problem solving service to people who have an identified biopsychosocial problem. The intervention is aimed at restoring the client's problem solving and coping capacities. The soldier is viewed first as a person, and only secondly as a soldier. Any intervention that addresses people's problems at a personal level falls into this position.

The presence of a problem may suggest that all position one interventions are therapeutic. Therapy, however, is only one form of problem resolution and is typically individually focused. Not only individuals, but also couples, families, groups and even whole communities can have problems. The size of the client system is irrelevant in the MilSWPM. When people request assistance in resolving their personal problems, a position one intervention is typically appropriate. It should be clear, then, that I avoid micro-macro distinctions in the MilSWPM. Case, group and community work all have a place in position one.

In order for a problem solving intervention to be located in position one, it should not directly address the work-person interface. Position one interventions thus address problems that are primarily of a personal nature, e.g. substance abuse, marital distress, adjustment difficulties, child abuse, family problems, financial difficulties, poor sanitation, and high crime rates. Work-related problems may be addressed, but the intervention in this position does not directly aim to facilitate the work-person interface. If, for example, a client presents with alcohol dependency that is influencing his/her work, a position one intervention could be to enable sobriety. As soon as the social worker focuses directly on the fit between the soldier and his/her work (e.g. should the worker be dismissed or not?), s/he has moved to position three. Because binocular vision is relevant at all four positions, it is important to note that although position one interventions address the employee-as-person, the person is also an employee. It is thus likely that her/his functioning in the workplace will also be impacted by the intervention, albeit indirectly. 
In brief, then, position one interventions are directed at helping people resolve their problems at a personal, non-work-related level so as to restore healthy psychosocial functioning.

\section{Position Two: Promotive Interventions}

In this position the military social worker renders a preventive, educational and developmental social work service. These interventions are aimed at promoting or enhancing the social functioning of people. These people have psychosocial needs that the social worker assists in fulfilling. As in the previous position, soldiers are viewed first as people and only secondly as soldiers. Any intervention that addresses the needs of people (rather than their problems) at a personal level falls into this position.

Positions one and two are similar in most respects, except one: rather than problem resolution, position two focuses on promotion of need fulfillment, thus an emphasis on building resilience and adopting a strengths perspective. Promotive interventions may aim to prevent the escalation of a social problem that would require restorative interventions, thereby promoting the human need for well-being. The social worker may also assist clients who have an unalterable problem, but who desire to live more fully despite the problem. A psychoeducational intervention for the families of schizophrenic patients is an example of this.

A broad range of interventions is possible in position two. The military social worker may make use of case work, group work, community work, psychoeducational workshops, lectures, seminars, pamphlet and poster campaigns, and exhibitions. As in position one, the client system covers the full micro-macro range and interventions are addressed at a personal level; interventions that directly address the worker-work interface fall into position three (although binocularity simultaneously argues that a position two intervention will, indirectly, impact on the clients' job performance).

In summary, position two interventions aim at promoting healthy psychosocial functioning and resilience by facilitating people's needs at a personal, non-workrelated level.

\section{Position Three: Work-person Interventions}

In this position the military social worker addresses the systems of interpersonal relationships within the workplace in order to produce a productive work community. Interfaces between the workplace and other systems (e.g. the family or community) are also important in this position. Any intervention that addresses people in relation to the work setting falls into position three.

The fundamental distinction between the first two and last two positions is that the military social worker's attention now shifts to the interface between the soldier (worker) and the military (workplace). As soon as an intervention seeks to facilitate the ability of people to fit with the workplace (including colleagues, managers and the organization itself), the social worker has moved to position three.

Conceptually, the military social worker endeavors to facilitate the interfaces between the workplace and people (hence Work-Person Interventions). The interface will often be between workers themselves, or between a worker and the workplace. 
Position three interventions may also focus on the interface between the workplace and the soldier's family, particularly when families are helped to tolerate or transcend military demands (e.g. the Deployment Resilience Seminar).

In this position the military social worker may utilize group work techniques, problem solving processes, experiential exercises, community development, team building, community building, negotiation, mediation, and participation in committees and workgroups.

In brief, then, position three interventions strive to promote a healthy workperson interface by addressing soldiers in relation to the military setting.

\section{Position Four: Workplace Interventions}

In the fourth position the military social worker focuses on the military as an organization so as to create a conducive work milieu. Here the worker is interested in establishing standard practices, structures, processes and policies that will benefit the functioning of the organization and thereby also the employee. This entails a more radical approach to social work practice, focused on structural or systemic changes at macro level. Any intervention that addresses the workplace itself falls into position four.

Positions three and four are similar inasmuch as both address the work-person interface. While position three focuses on people, however, position four focuses on the workplace itself. Where position three endeavored to enable soldiers to adjust to the needs of the military, position four endeavors to enable the military to adjust to the needs of soldiers.

The military social worker works with the organizational dimensions within which soldiers function. While there may be a complete turnover of soldiers in a particular unit, the unit itself remains the same; individual soldiers are simply present in the unit at this point in time. These organizational dimensions can include the structure or hierarchy, culture, processes and procedures, policies, politics, setting, and physical layout.

The role of the military social worker is that of change-management consultant, social activist, social engineer, policy maker, systems analyst, researcher, and organizational development consultant. The social worker assists the workplace in developing a structure or way of working that promotes optimal productivity, effectiveness, morale and social well-being among employees. The worker plays an integral part in the management of the workplace, being a specialist on the interface between an impersonal organization and a personal workforce. In focusing on this interface, the social worker humanizes and may serve as the social conscience of the organization.

In conclusion, position four interventions target the workplace itself for the reciprocal benefit of both the military and the soldiers (and their families).

\section{PRACTICE EXAMPLES}

The SANDF is one of the largest employers of military social workers in South Africa. A complete range of social work services is provided to military employees, their families and the SANDF itself. Only statutory cases are referred to outside 
welfare agencies. This section provides brief practice examples for binocular vision and the four positions.

\section{Binocular Vision}

Previously I suggested that the creative potential of binocular vision could be realized by seeking out the most problematic point of interface between soldiers and the military. In most military contexts this point is located at the military's requirement of operational readiness. Operational readiness is the military's demand that all employees are able to perform operational duties (e.g. peace keeping missions and combat operations) at any time (Segal \& Harris, 1993).

The SANDF has addressed itself largely to ensuring that soldiers are capable of performing their tasks and functions during military operations. Limited attention has been given to the emotional dimensions of operational readiness, let alone to the effects on and role of families.

As a result, in the mid-1990s SANDF social workers conducted several research projects to evaluate the impact of operational readiness on employees and their families, to evaluate the effect of families on the operational readiness of the organization and on the characteristics of a good fit between families/soldiers and the organization in terms of operational readiness (Herbst, 1995; Kruger, 1997; Mathee, 1997; Van Breda, 1997a).

In this research we can clearly see binocular vision at work. The studies were able to assess both the military's and the family's contribution to operational readiness and the factors which social workers needed to promote to ensure (a) well functioning families and soldiers, (b) an operationally ready organization, and (c) a good fit between soldiers and the military.

\section{Position One: Restorative Interventions}

Vignette 1. One social worker worked with a young man whose chaotic childhood had left him with a disordered personality, which impacted on all areas of his life. The social worker focused on the client's personal relationships and selfesteem. The client's sense of adequacy improved which reflected positively in his private and work lives. The intervention aimed at restoring the client's ability to relate to others in a positive and productive way.

Vignette 2. Another social worker was struck by the number of battered wives seen in her unit. She therefore began a weekly treatment group for these women that replaced their individual therapy. The social worker taught the women about the cycle of battering, their legal rights and the community resources available to them and facilitated on-going problem solving. This group work intervention entailed the restoration of personal power.

\section{Position Two: Promotive Interventions}

Vignette 1. One social worker ran a stress management course for the management team of his unit at the request of the Commanding Officer, who wished to enhance the well-being of his team members. The course ran for three days and addressed a broad range of principles and techniques of stress management. In the process, a more personal level of interaction developed in the management team that 
had not been evident before. This course was intended to enhance and promote the clients' personal functioning.

Vignette 2. A clinical social worker was approached by a soldier who was interested in her dreams. The social worker assessed the client's functioning and found no significant psychosocial problems. They worked for several months, making sense of the client's dream life. The social worker sought to promote the client's individuation or self-actualization.

\section{Position Three: Work-person Interventions}

Vignette 1. I developed a psychoeducational program that contributes to the operational readiness of military employees and their families (Van Breda, 1997a, 1999). The program develops seven factors that are present in families who are resilient to the repeated separation of a soldier from the family unit. In so doing, this program promotes the family's ability to fit with a stressful organizational demand.

Vignette 2. Another social worker was consulted by a soldier who had significant frustrations with his supervisor at work. After assessing the problem, it appeared that there was a conflict of interest between the client and his supervisor. The social worker suggested that she mediate between them. Both the soldier and his supervisor agreed that the mediation was valuable in ameliorating a long-standing work conflict between them.

\section{Position Four: Workplace Interventions}

Vignette 1. One social worker heard repeated complaints from black African members of her unit that only Western food was being served in their living quarters. The social worker formed a joint employee-management committee and facilitated discussions, which led to a change in the unit's provision of food - traditional African food was also served. This worker used community work processes to address a problem of organizational culture.

Vignette 2. A social worker was concerned that naval management should address its own role in the operational readiness of naval families. He therefore wrote several reports to his unit and to naval headquarters, making recommendations on how to reduce the deployment stress of sailors and their families. In meetings he emphasized how executing these recommendations would enhance the operational readiness of the unit (thereby emphasizing the problematic point of interface). This led to the formation of a work team at naval headquarters to address the matter.

\section{CONCLUSIONS}

MilSW in South Africa has evolved over the years with its own distinctive flavor. This evolvement has been shaped by a variety of contextual factors, particularly the transition from Apartheid to a non-racial democracy in 1994. Three other relevant contextual factors include engagement with military families, the establishment of a dedicated MilSW research capacity and the implementation of a series of social work supervision courses. In raising these four contextual factors, I hope to have shown how MilSW thinking takes place within particular local contexts and does not exist in the abstract. 
The implication is that if we hope to see further evolvement in MilsW thinking (including theory development) militaries need to create or capitalize on existing contextual factors. It is noteworthy that two of four factors identified involved creating spaces for social workers to step away from action and into reflection. A third factor involved social workers taking a 'one-down' position and learning from their clients. A fourth factor involved locating MilSW more squarely in the mainstream of developments within social work and social welfare at national and international levels. All four of these factors disturbed the MilSW status quo and demanded new ways of thinking about practice.

The MilSWPM has been advanced as a central exemplar of this kind of new thinking in South Africa. It illustrates MilSW's engagement with a body of theory (primarily occupational social work, but also elements of developmental social welfare, ecosystems, cybernetics and psychoanalytic theories) and the critical integration of selected aspects of this theory into our own understanding of MilSW. The new thinking is also spurred on and informed by real-world practice concerns, such as the tendency of military social workers to ally with either soldiers or military management or the perception that good MilSW practice involves abandoning micro practice in favor of macro practice.

In addition, most of the developments noted in the preceding section have influenced the conceptualization of the MilSWPM. For example, the notions of working to change the military system itself, rather than aiming to change only the individuals within the system, were informed by the transition to democracy, the emergence of developmental social welfare, and a greater commitment to social action and structural change. The notions of resilience shaped the understanding of Promotive Interventions and Work-Person Interventions, both of which emphasize a striving for balance, rather than the elimination of pathology.

The MilSWPM, in itself, serves to advance our thinking about MilSW. It is the only substantive model of MilSW available in the literature. While it has been discussed in various publications (Daley, 2003; Kruger \& Van Breda, 2001; Van Breda, 2009; Van Breda \& Du Plessis, 2009), this is the most comprehensive published presentation of the model. It is hoped that the model may expand and guide MilSW practice in other militaries, stimulating the development of new knowledge and theory.

\section{References}

ANC. (1994). The reconstruction and development programme: A policy framework. Johannesburg, RSA: African National Congress.

Antonovsky, A. (1988). Unraveling the mystery of health: How people manage stress and stay well. San Francisco, CA: Jossey-Bass.

Applewhite, L. W., Hamlin, E. R., BrintzenhofeSzoc, K., \& Timberlake, E. M. (1995). Clinical social work practice in the U.S. Army: An update. Military Medicine, 160(6), 283-288.

Casement, P. (1985). On learning from the patient. London, UK: Routledge.

Daley, J. G. (2003). Military social work: A multi-country comparison. International Social Work, 46(4), 437-448. 
De Klerk, M. H. (1991). Organisatoriese en strukturele aspekte van militere maatsakplikewerkdients [Organisational and structural aspects of military social work services]. Unpublished master's dissertation, University of Stellenbosch, Stellenbosch, RSA.

Du Plessis, A. W. (1994). Issue resolution in the evolvement of occupational social work practice in South Africa. Unpublished doctoral dissertation, University of the Witwatersrand, Johannesburg, South Africa.

Du Plessis, A. W. (2001). Occupational social work in South Africa. Employee Assistance Quarterly, 17(1/2), 97-118.

Gitterman, A., \& Germain, C. B. (2008). The life model of social work practice: Advances in theory and practice ( $3^{\text {rd }}$ ed.). New York: Columbia University Press.

Googins, B. (1987). Occupational social work: A developmental perspective. Employee Assistance Quarterly, 2(3), 37-53.

Googins, B., \& Davidson, B. N. (1993). The organization as client: Broadening the concept of employee assistance programs. Social Work, 38(4), 477-484.

Googins, B., \& Godfrey, J. (1987). Occupational social work. Englewood Cliffs, NJ: Prentice-Hall.

Herbst, A. G. (1995). Militêre skeiding: Hoe raak dit ons kinders [Military separation: How does it affect our children]. Milmed, 11(3), 12-16.

Hinshelwood, R. D. (1991). A dictionary of Kleinian thought. London: Free Association Books.

Hollis, F., \& Woods, M. E. (1981). Casework: A psychosocial therapy ( $3^{\text {rd }}$ ed.). New York City, NY: Random House.

Keeney, B. P. (1983). Aesthetics of change. New York: Guilford Press.

Kruger, A. (1997). Die oorgang van die militere gesinsisteem na ouerskap [The transition to parenthood of the military family system]. Unpublished master's dissertation, Stellenbosch University, Stellenbosch, RSA.

Kruger, A., \& Van Breda, A. D. (2001). Military social work in the South African National Defence Force. Military Medicine, 166(11), 947-951.

Logan, K. V. (1987). The emotional cycle of deployment. Proceedings, 113(2), 4347.

Mathee, A. (1997). Die effek van militêre ontplooing op die soldaat in Kwazulu-Natal met spesifieke verwysing na die gesin [The effect of military deployment on the soldier in Kwazulu-Natal with specific reference to the family]. Unpublished master's thesis, University of South Africa, Pretoria, South Africa.

McCubbin, H. I., \& Lavee, Y. (1986). Strengthening army families: A family life cycle stage perspective. Evaluation and Program Planning, 9(3), 221-232.

Midgley, J. (2001). South Africa: The challenge of social development. International Journal of Social Welfare, 10(4), 267-275.

Ortiz, E. T., \& Bassoff, B. Z. (1987). Military EAPs: Emerging family service roles for social workers. Employee Assistance Quarterly, 2(3), 55-67. 
Ozawa, M. N. (1980). Development of social services in industry: Why and how? Social Work, 25(6), 464-469.

Patel, L. (2005). Social welfare and social development in South Africa. Cape Town, RSA: Oxford.

RSA. (1996). Constitution of the Republic of South Africa, Act 108 of 1996. Pretoria, South Africa: Government Printers.

RSA. (1997). White Paper for Social Welfare (Government Gazette, Vol. 386, No. 18166, 8 August). Pretoria, South Africa: Government Printer.

Saleebey, D. (Ed.). (2008). The strengths perspective in social work practice ( $5^{\text {th }}$ ed.). Boston, MA: Allyn \& Bacon.

Segal, M. W., \& Harris, J. J. (1993). What we know about army families (Special Report 21; Contract No DAAL03-86-D-0001). Alexandria, VA: US Army Research Institute for the Behavioral and Social Sciences.

Uys, F. (1997). The SANDF transformation process. African Security Review, 6(1), 58-63.

Van Breda, A. D. (1997a). The development of the Deployment Resilience Seminar. Unpublished Master's Thesis, University of Cape Town, Cape Town, RSA.

Van Breda, A. D. (1997b). Experience of routine husband absences. Social Work / Maatskaplike Werk, 33(2), 154-164.

Van Breda, A. D. (1998, February). Developing resilience to deployments. Paper presented at the national conference on Police as Victims of Trauma and Crisis, Technikon South Africa, Johannesburg, South Africa.

Van Breda, A. D. (1999). Developing resilience to routine separations: An occupational social work intervention. Families in Society, 80(6), 597-605.

Van Breda, A. D. (2001). Resilience theory: A literature review. Pretoria, South Africa: South African Military Health Service.

Van Breda, A. D. (2002a, 15-20 September). Military social work research in South Africa. Paper presented at the 34th International Congress on Military Medicine, Sun City, South Africa.

Van Breda, A. D. (2002b, 15-20 September). Social health assessment of soldiers' operational readiness. Paper presented at the 34th International Congress on Military Medicine, Sun City, South Africa.

Van Breda, A. D. (2008). The Military Social Health Index: A partial multicultural validation. Military Medicine, 173(5), 480-487.

Van Breda, A. D. (2009). The scope of occupational social work in South Africa. Social Work Practitioner-Researcher, 21(3), 281-297.

Van Breda, A. D. (2011). Resilience assessments in social work: The case of the SA Department of Defence. Social Work / Maatskaplike Werk, 47(1), 1-14.

Van Breda, A. D., \& Du Plessis, A. W. (2009). A model of occupational social work practice: A developmental social welfare critique. Social Work PractitionerResearcher, 21(3), 316-333. 


\section{Author's note:}

Address correspondence to: Professor Adrian D. van Breda, Department of Social Work, University of Johannesburg, PO Box 2354, Rooihuiskraal, 0154, South Africa.

E-mail: adrian@vanbreda.org 